\title{
Fault diagnosis of a squirrel cage induction motor fed by an inverter using lissajous curve of an auxiliary winding voltage
}

\author{
Yakout Khadouj Jelbaoui $^{1}$, El Menzhi Lamiaà ${ }^{2}$, Abdallah Saad ${ }^{3}$ \\ ${ }^{1,2}$ National School of Applied Sciences, Abdelmalek Essaadi University, Morocco \\ ${ }^{3}$ National Higher School of Electricity and Mechanic, Hassan 2 University, Casablanca 8118, Morocco
}

\begin{tabular}{|c|c|}
\hline Article Info & ABSTRACT \\
\hline & \multirow{10}{*}{$\begin{array}{l}\text { The development of power electronic components has allowed the increase } \\
\text { of the induction machine performance. Indeed, monitoring squirrel cage } \\
\text { induction motors driven through rectifiers and inverters has been a major } \\
\text { concern. This paper presents a new method to diagnose the combination } \\
\text { inverter-machine faults. This technic considers an auxiliary winding which is } \\
\text { a small coil inserted between two stator phases. It is based on Lissajous curve } \\
\text { of this auxiliary winding voltage Park components. For this purpose, } \\
\text { modeling the electromechanical conversion chain is necessary. The focus } \\
\text { will particularly be on modeling both the squirrel cage induction machine } \\
\text { and the inverter in a non-defected case which is a reference. Moreover, the } \\
\text { explicit expressions developed for the inserted winding voltage and its Park } \\
\text { components will be presented. The simulation results show the effectiveness } \\
\text { of the proposed method. }\end{array}$} \\
\hline Received Jul 17, 2020 & \\
\hline Revised Dec 1, 2020 & \\
\hline Accepted Jan 5, 2021 & \\
\hline Keywords: & \\
\hline Auxiliary winding voltage & \\
\hline Diagnosis & \\
\hline Inverter & \\
\hline Lissajous curve & \\
\hline Squirrel cage motor & \\
\hline
\end{tabular}

This is an open access article under the CC BY-SA license.

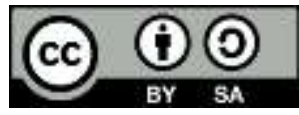

\section{Corresponding Author:}

Yakout Khadouj Jelbaoui

Department of Electrical and Industrial System

National School of Applied Sciences, Tangier 90000, Morocco

Abdelmalek Essaâdi University, Morocco

Email: jelbaoui.yakout@ gmail.com

\section{INTRODUCTION}

Through considerable technological progress in the power electronics field over recent years, the power electronic converters are extensively used in different applications making varying speed drive of induction machines possible by adjusting the frequency of the applied voltages. This amount use refers to the ability of these converters to improve the static and dynamic characteristics efficiency and limit the requirements of machines, due to high capability of the inverter to ensure flexible voltage and frequency variation, which is the case of electromechanical conversion chain.

The electromechanical conversion chain is a structure that is widely used and occupies a privileged place in the industrial sector. It consists of a squirrel cage induction machine fed by a power electronic inverter connected to a rectifier that converts the alternative voltage to the continuous one, fed by a transformer related to a power grid of a medium distribution voltage as shown in Figure 1. The connection between the rectifier and the inverter called DC link and it is generally equipped with a filter.

The squirrel cage induction machine is the principal drive in our chain, it is known for its simplicity, robustness and its low maintenance cost. Associating this machine with the power devices adds extremely interesting performance to be used in variable speed drives. In this case, the machine is not fed directly from the power grid but supplied from a switched voltage waveform created by an inverter. This voltage will change because of many reasons [1] such as one or multiple of its power switches fail that can lead to critical damage throughout the chain especially the motor. 


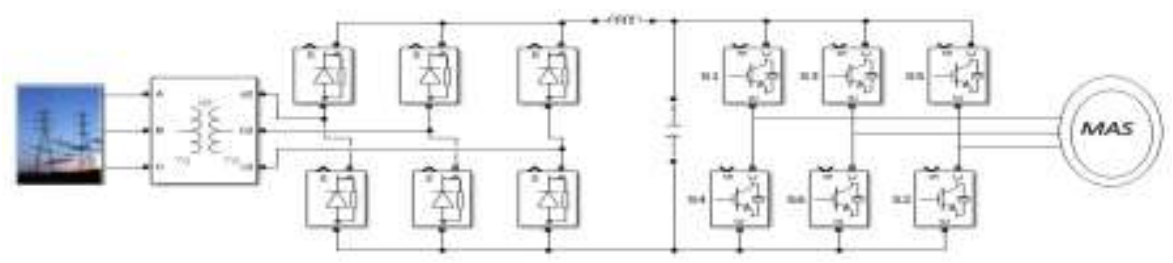

Figure 1. Electromechanical conversion chain

Despite all the squirrel cage induction motor advantages, no industrial system is immune from failure. Therefore, a monitoring system and online diagnosis become a must for anticipating the risk of a defect with incipient fault detection for instance. According to signals nature, different technics have been used for rotor faults such as broken rotor bars, broken end rings and eccentricity [2, 3]. For instance, motor current signature analysis (MCSA) is one of the instruments used for monitoring the induction machine, it focuses on the spectram analysis of the stator current with evaluating the amplitude of the appearing current harmonics over a constant torque [4, 5]. On the other hand, wavelet transform (WT) is required for nonconstant torque or nonstationary signals, this method can be divided into two types discrete (DWT) [6] and continuous wavelet transform (CWT) [7]. The fast fourier transform spectral signature analysis (FFT) [8, 9] is the most popular technic for detecting broken rotor bars fault. This method is limited only on stationary and linear signals. Moreover, it presents problems to analyse noisy signals $[10,11]$. There are also vibration signals and current signals approach which present a problem during the acquisition of mechanical signal or current signature related to failure [12].

This paper presents a new diagnosis methodology based on the so-called auxiliary winding voltage signal approach. In fact, the aim of this technic is monitoring the voltage of an auxiliary small coil "sneak" inserted between two of the stator phases. This analytical procedure is expected to yield accurate predictions regarding monitoring squirrel cage induction machine failures through the Lissajous curve of the auxiliary winding voltage [13]. For that purpose, modeling of the combination inverter-squirrel cage induction machine as a meshed circuit is presented.

\section{INVERTER - SQUIRREL CAGE INDUCTION MACHINE MODELING}

Explaining the squirrel cage motor the three-phase DC/AC inverters turn out to be one of the most circuit configuration used for induction machine speed control due to their high capability to ensure flexible voltage and frequency variation [14].

Three-leg inverter consists of six IGBT's with anti-parallel diodes for bidirectional power flow. The insulated gate bipolar transistor is a semiconductor device that can combine high efficiency and fast switching. The two switches $S_{j}, \bar{S}_{J}$ in the same leg cannot be turned ON at the same time. They are complementary. Their state is defined as:

$$
S_{j}=\left\{\begin{array}{l}
+1 \\
-1
\end{array} \overline{S_{j}}=\left\{\begin{array}{l}
+1 \\
-1
\end{array} \text { with } j=a, b, c\right.\right.
$$

As we are dealing with balanced three phase voltages, we have $V_{a n}+V_{b n}+V_{c n}=0$, thus we found $V_{n 0}$ as:

$$
V_{n 0}=\frac{V_{a 0}+V_{b 0}+V_{c 0}}{3}
$$

From (2) the line-to-neutral voltages are presented in matrix form as:

$$
\left[\begin{array}{l}
V_{a n} \\
V_{b n} \\
V_{c n}
\end{array}\right]=\frac{1}{3}\left[\begin{array}{ccc}
2 & -1 & -1 \\
-1 & 2 & -1 \\
-1 & -1 & 2
\end{array}\right]\left[\begin{array}{l}
V_{a 0} \\
V_{b 0} \\
V_{c 0}
\end{array}\right]
$$

Where the three leg voltage $\left(V_{a 0} V_{b 0} V_{c 0}\right)$ is measured relatively to the negative terminal of the DC voltage $(\mathrm{E})$, and the phase voltage $\left(V_{a n} V_{b n} V_{c n}\right)$ measured relative to the neutral $\mathrm{N}$. The AC output line voltages $\left(V_{a b} V_{b c} V_{c a}\right)$ can only switch between these voltages values $E, 0$. and $-E$.

A three-leg inverter has eight possible switching-states (000 111) including six non-zero voltage vectors and two zero voltage vectors $(000,111)$ which are listed in Table 1 [15]. 


\begin{tabular}{cccccccccc}
\multicolumn{10}{c}{ Table 1. The switching states in a three-phase inverter } \\
\hline$S_{a}$ & $S_{b}$ & $S_{c}$ & $V_{a 0}$ & $V_{b 0}$ & $V_{c 0}$ & $V_{n 0}$ & $V_{a n}$ & $V_{b n}$ & $V_{c n}$ \\
\hline 0 & 0 & 0 & 0 & 0 & 0 & 0 & 0 & 0 & 0 \\
0 & 0 & 1 & 0 & 0 & $E$ & $\frac{E}{3}$ & $-\frac{E}{3}$ & $-\frac{E}{3}$ & $\frac{2 E}{3}$ \\
0 & 1 & 0 & 0 & $E$ & 0 & $\frac{E}{3}$ & $-\frac{E}{3}$ & $\frac{2 E}{3}$ & $-\frac{E}{3}$ \\
0 & 1 & 1 & 0 & $E$ & $E$ & $\frac{2 E}{3}$ & $-\frac{2 E}{3}$ & $\frac{E}{3}$ & $\frac{E}{3}$ \\
1 & 0 & 0 & $E$ & 0 & 0 & $\frac{E}{3}$ & $\frac{2 E}{3}$ & $-\frac{E}{3}$ & $-\frac{E}{3}$ \\
1 & 0 & 1 & $E$ & 0 & $E$ & $\frac{2 E}{3}$ & $\frac{E}{3}$ & $-\frac{2 E}{3}$ & $\frac{E}{3}$ \\
1 & 1 & 0 & $E$ & $E$ & 0 & $\frac{2 E}{3}$ & $\frac{E}{3}$ & $\frac{E}{3}$ & $-\frac{2 E}{3}$ \\
1 & 1 & 1 & $E$ & $E$ & $E$ & $E$ & 0 & 0 & 0 \\
\hline
\end{tabular}

A squirrel cage induction motor model is built considering that the stator is a three phase winding and the rotor cage can be regarded as a whole of meshes representing the $N_{r}$ rotor bars similarly separated and short-circuited together by two identical end rings as shown in Figure 2.

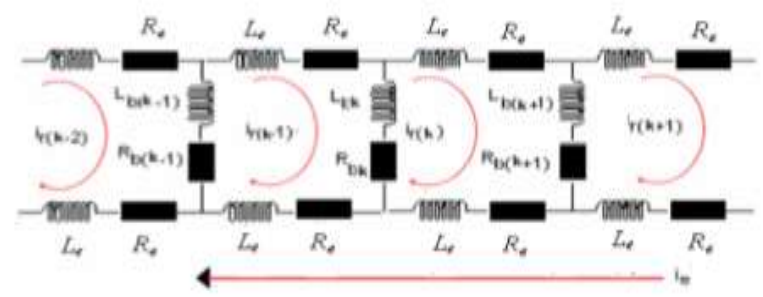

Figure 2. Multi-winding model of a cage asynchronous motor

$I_{r k}$ with $k=1 \ldots N_{r}$ are the $N_{r}$ rotor loops current and $i_{e}$ is one of the end rings current.

These loops are connected between them electrically and coupled magnetically. The current in each circuit is considered as an independent variable. The induction motor model takes into account the machine geometric construction and the following assumptions $[16,17]$ :

a) Sinusoidally distributed stator windings.

b) Infinity iron permeability.

c) Neglecting saturation.

d) Uniform air gap.

e) Neglecting inter-bar currents.

f) Evenly distributed rotor bars.

g) Neglecting flux coupling between different winding without air gap crossing

The motor matrix mathematical model can be written as:

$$
\left[\mathrm{V}_{\mathrm{s}}\right]=\left[\mathrm{R}_{\mathrm{s}}\right]\left[\mathrm{I}_{3 \mathrm{~s}}\right]+\frac{\mathrm{d}\left[\phi_{3 \mathrm{~s}}\right]}{\mathrm{dt}}
$$

With,

$$
\begin{aligned}
& {\left[\phi_{3 s}\right]=\left[\mathrm{L}_{\mathrm{s}}\right]\left[\mathrm{I}_{3 \mathrm{~s}}\right]+\left[\mathrm{M}_{\mathrm{sr}}\right]\left[\mathrm{I}_{\mathrm{r}}\right]} \\
& {\left[\begin{array}{c}
{\left[\mathrm{V}_{\mathrm{r}}\right]} \\
\mathrm{V}_{\mathrm{e}}
\end{array}\right]=[0]=\left[\begin{array}{cc}
{\left[\mathrm{R}_{\mathrm{r}}\right]} & \frac{\mathrm{R}_{\mathrm{e}}}{\mathrm{N}_{\mathrm{r}}} \\
\frac{\mathrm{R}_{\mathrm{e}}}{\mathrm{N}_{\mathrm{r}}} & \mathrm{R}_{\mathrm{e}}
\end{array}\right]\left[\begin{array}{c}
{\left[\mathrm{I}_{\mathrm{r}}\right]} \\
\mathrm{i}_{\mathrm{e}}
\end{array}\right]+\frac{\mathrm{d}}{\mathrm{dt}}\left[\begin{array}{c}
{\left[\phi_{\mathrm{r}}\right]} \\
\phi_{\mathrm{e}}
\end{array}\right]} \\
& {\left[\begin{array}{c}
{\left[\phi_{\mathrm{r}}\right]} \\
\phi_{\mathrm{e}}
\end{array}\right]=\left[\begin{array}{c}
{\left[\mathrm{M}_{\mathrm{rs}}\right]\left[\mathrm{I}_{\mathrm{s}}\right]} \\
0
\end{array}\right]+\left[\begin{array}{cc}
{\left[\mathrm{L}_{\mathrm{r}}\right]} & \frac{\mathrm{L}_{\mathrm{e}}}{\mathrm{N}_{\mathrm{r}}} \\
\frac{\mathrm{L}_{\mathrm{e}}}{\mathrm{N}_{\mathrm{r}}} & \mathrm{L}_{\mathrm{e}}
\end{array}\right]\left[\begin{array}{c}
{\left[\mathrm{I}_{\mathrm{r}}\right]} \\
\mathrm{i}_{\mathrm{e}}
\end{array}\right]}
\end{aligned}
$$


Where, $[\mathrm{V}]$ is the voltage vector, $[\mathrm{I}]$ is the currents vector, $\left[\mathrm{R}_{\mathrm{s}}\right]_{3 \times 3}$ and $\left[\mathrm{R}_{\mathrm{r}}\right]_{N r \times N r}$ are the stator and the rotor resistances matrixes respectively. Whereas $\left[\mathrm{L}_{\mathrm{S}}\right]_{3 \times 3}$ is the stator winding inductance matrix, $\left[\mathrm{L}_{\mathrm{r}}\right]_{N r \times N r}$ is the rotor inductance matrix, $\left[\mathrm{M}_{\mathrm{sr}}\right]_{3 \times N r}$ is the mutual inductance matrix between stator and rotor. $\left[\phi_{\mathrm{s}}\right]$ and $\left[\phi_{\mathrm{r}}\right]$ are the stator and rotor fluxes vectors respectively.

Furthermore,

$$
\begin{aligned}
& {\left[R_{s}\right]=\left[\begin{array}{ccc}
\mathrm{R}_{\mathrm{s}} & 0 & 0 \\
0 & \mathrm{R}_{\mathrm{s}} & 0 \\
0 & 0 & \mathrm{R}_{\mathrm{s}}
\end{array}\right]} \\
& {\left[\mathrm{R}_{\mathrm{r}}\right]=\left[\begin{array}{cccccc}
\mathrm{R}_{\mathrm{b} 0}+\mathrm{R}_{\mathrm{b}\left(\mathrm{N}_{\mathrm{r}}-1\right)}+2 \frac{\mathrm{R}_{\mathrm{e}}}{\mathrm{N}_{\mathrm{r}}}-\mathrm{R}_{\mathrm{b} 1} & \cdots & 0 & \cdots & -\mathrm{R}_{\mathrm{b}\left(\mathrm{N}_{\mathrm{r}}-1\right)} \\
-\mathrm{R}_{\mathrm{b} 1} & \vdots & \cdots & \vdots & \cdots & 0 \\
0 & \vdots & \cdots & \mathrm{R}_{\mathrm{bk}}+\mathrm{R}_{\mathrm{b}(\mathrm{k}-1)}+2 \frac{\mathrm{R}_{\mathrm{e}}}{\mathrm{N}_{\mathrm{r}}} \cdots & \mathrm{R}_{\mathrm{b}\left(\mathrm{N}_{\mathrm{r}}-2\right)}+\mathrm{R}_{\mathrm{b}\left(\mathrm{N}_{\mathrm{r}}-1\right)}+2 \frac{\mathrm{R}_{\mathrm{e}}}{\mathrm{N}_{\mathrm{r}}}
\end{array}\right]}
\end{aligned}
$$

According to winding function approach, the inductance between two windings ' $\mathrm{i}$ ', and ' $\mathrm{j}$ ', in any electric machine can be calculated by the following [18] and [19]:

$$
\mathrm{L}_{i j}(\varphi)=\mu_{0} \operatorname{Lr} \int_{0}^{2 \pi} \frac{\mathrm{n}_{i}(\varphi, \theta) \mathrm{N}_{j}(\varphi, \theta)}{\mathrm{e}(\varphi, \theta)} \mathrm{d} \theta
$$

$\mathrm{n}_{i}(\varphi, \theta)$ is the winding distribution of coil ' 'i', $\mathrm{N}_{j}(\varphi, \theta)$ is the winding function of coil ' $\mathrm{j}$ '". It represents the magneto motive force distribution along the air gap. $\varphi$ is the rotor angular position, $\theta$ is the particular angular position along the stator inner surface, e is the air gap length, $r$ is the average radius of the air gap and L is the motor effective stack length [20].

We add the leakage inductances to the self-inductances. Therefore, the inductances matrices can be obtained from (10) as follows [21, 22]:

$$
\begin{aligned}
& {\left[L_{s}\right]=\left[\begin{array}{ccc}
L_{s p}+L_{s f} & M_{s_{a} s_{b}} & M_{s_{a} s_{c}} \\
M_{s_{b} s_{a}} & L_{s p}+L_{s f} & M_{s_{b} s_{c}} \\
M_{s_{c} s_{a}} & M_{s_{c} s_{b}} & L_{s p}+L_{s f}
\end{array}\right]} \\
& {\left[\mathrm{L}_{\mathrm{r}}\right]=}
\end{aligned}
$$

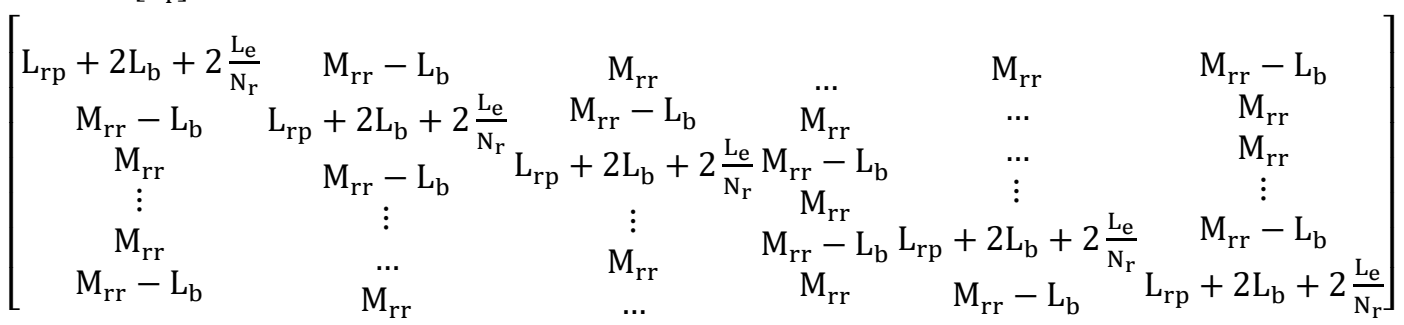

And,

$$
\left[\mathrm{M}_{\mathrm{sr}}\right]=\left[\begin{array}{ccc}
\ldots & -\mathrm{L}_{\mathrm{sr}} \cos (\theta+\mathrm{ka}) & \ldots \\
\ldots & -\mathrm{L}_{\mathrm{sr}} \cos (\theta+\mathrm{ka}-2 \pi / 3) & \ldots \\
\ldots & -\mathrm{L}_{\mathrm{sr}} \cos (\theta+\mathrm{ka}-4 \pi / 3) & \ldots
\end{array}\right], \text { avec }\left[\mathrm{M}_{\mathrm{rs}}\right]=\left[\mathrm{M}_{\mathrm{sr}}\right]^{\mathrm{T}}
$$

Using park transformation in the case of a fixed rotor reference frame, we transform the three-phase stator windings $\mathrm{a}, \mathrm{b}$ and $\mathrm{c}$ in three orthogonal $\mathrm{d}$, $\mathrm{q}$ and o windings. The overall mathematical model machine equations in the axis system $\mathrm{d}$, q can be written as follows:

$$
\frac{\mathrm{d}[\mathrm{I}]}{\mathrm{dt}}=-[\mathrm{L}]^{-1}\left([\mathrm{R}]+\frac{\mathrm{d}[\mathrm{L}]}{\mathrm{dt}}\right)[\mathrm{I}]-[\mathrm{L}]^{-1}[\mathrm{~V}]
$$


Where $[\mathrm{I}]=\left[\begin{array}{c}{\left[\mathrm{I}_{\mathrm{dqo}}\right]} \\ {\left[\mathrm{I}_{\mathrm{r}}\right]} \\ \text { ie }\end{array}\right],[\mathrm{V}]=\left[\begin{array}{c}{\left[\mathrm{V}_{\mathrm{dqo}}\right]} \\ {\left[\mathrm{V}_{\mathrm{r}}\right]=0} \\ \mathrm{Ve}=0\end{array}\right]$

The globale résistance and inductance matrixes can be written as:

$$
\begin{aligned}
& {[R]=\left[\begin{array}{ccc}
{\left[\mathrm{R}_{\mathrm{s}}\right]} & {[0]} & {[0]} \\
{[0]} & {\left[\mathrm{R}_{\mathrm{r}}\right]_{\mathrm{Nr} \times \mathrm{Nr}}} & -\frac{\mathrm{Re}_{\mathrm{e}}}{\mathrm{N}_{\mathrm{r}}}[1]_{\mathrm{Nr} \times 1} \\
{[0]} & -\frac{\mathrm{R}_{\mathrm{e}}}{\mathrm{N}_{\mathrm{r}}}[1]_{1 \times \mathrm{Nr}} & \mathrm{R}_{\mathrm{e}}
\end{array}\right]} \\
& {[\mathrm{L}]=\left[\begin{array}{ccc}
{\left[\mathrm{L}_{\mathrm{s}}\right]} & {\left[\mathrm{M}_{\mathrm{sr}}\right]} & {[0]} \\
{\left[\mathrm{M}_{\mathrm{rs}}\right]} & {\left[\mathrm{L}_{\mathrm{r}}\right]_{\mathrm{Nr} \times \mathrm{Nr}}} & -\frac{\mathrm{L}_{\mathrm{e}}}{\mathrm{N}_{\mathrm{r}}}[1]_{\mathrm{Nr} \times 1} \\
{[0]} & -\frac{\mathrm{L}_{\mathrm{e}}}{\mathrm{N}_{\mathrm{r}}}[1]_{1 \times \mathrm{Nr}} & \mathrm{L}_{\mathrm{e}}
\end{array}\right]}
\end{aligned}
$$

According to the fundamental equation of dynamics, the evolution of the mechanical speed is expressed as below:

$$
\begin{aligned}
& \left\{\begin{array}{c}
\mathrm{J} \frac{\mathrm{d} \omega}{\mathrm{dt}}=\mathrm{C}_{\mathrm{em}}-\mathrm{C}_{\mathrm{r}}-\mathrm{f}_{\mathrm{v}} \omega \\
\omega=\frac{\mathrm{d} \theta}{\mathrm{dt}}
\end{array}\right. \\
& \mathrm{C}_{\mathrm{em}}=\sqrt{\frac{3}{2}} \mathrm{p} \mathrm{L}_{\mathrm{sr}}\left(\mathrm{I}_{\mathrm{qs}} \sum_{\mathrm{k}=0}^{\mathrm{Nr}-1} \mathrm{I}_{\mathrm{rk}} \cos (\mathrm{Ka})-\mathrm{I}_{\mathrm{ds}} \sum_{\mathrm{k}=0}^{\mathrm{Nr}-1} \mathrm{I}_{\mathrm{rk}} \sin (\mathrm{Ka})\right)
\end{aligned}
$$

With:

$$
L_{s r}=\frac{4 \mu_{0} N_{S} R L}{e \pi p^{2}} \sin (a / 2), a=\frac{2 \pi}{N_{r}} p \text { and } K=0, \ldots, N r
$$

Where $\mathrm{C}_{\mathrm{em}}$ is the electromagnetic torque, $\mathrm{C}_{\mathrm{r}}$ is the load torque, $\omega$ is the mechanical speed and $\mathrm{f}_{\mathrm{v}}$ is the friction coefficient. The geometric parameters $\mathrm{R}, \mathrm{L}$, and e are defined respectively as the air gap mean radius, the stack length, and the ring thickness.

\section{SQUIRREL CAGE INDUCTION MACHINE FED BY AN INVERTER SIMULATIONS}

\begin{tabular}{|c|c|c|}
\hline Symbol & quantity & Value \\
\hline $\mathrm{V}$ & Power supply voltage & $220 / 380 \mathrm{~V}$ \\
\hline $\mathrm{f}$ & Frequency & $50 \mathrm{~Hz}$ \\
\hline $\mathrm{p}$ & Number of pole pairs & 1 \\
\hline $\mathrm{N}_{\mathrm{r}}$ & Number of rotor bars & 27 \\
\hline $\mathrm{N}_{\mathrm{s}}$ & Number of & 193 \\
\hline $\mathrm{E}$ & Ring thickness & $0.38 \mathrm{~mm}$ \\
\hline $\mathrm{R}$ & Air gap mean radius & 37.5 \\
\hline $\mathrm{L}$ & Stack length & $60 \mathrm{~mm}$ \\
\hline $\mathrm{R}_{\mathrm{s}}$ & Resistant stator winding & $4.1 \Omega$ \\
\hline $\mathrm{R}_{\mathrm{b}}$ & Resistance of a rotor bar & $74 \mu \Omega$ \\
\hline $\mathrm{R}_{\mathrm{e}}$ & $\begin{array}{c}\text { Resistance of the rotor end } \\
\text { ring }\end{array}$ & $74 \mu \Omega$ \\
\hline $\mathrm{L}_{\mathrm{b}}$ & $\begin{array}{l}\text { Leakage inductance of } \\
\text { rotor bars }\end{array}$ & $0.33 \mu \mathrm{H}$ \\
\hline $\mathrm{L}_{\mathrm{e}}$ & $\begin{array}{l}\text { Leakage inductance of } \\
\text { rotor end rings }\end{array}$ & $0.33 \mu \mathrm{H}$ \\
\hline $\mathrm{J}$ & Moment of inertia & $4.510^{-3} \mathrm{Nms}^{2}$ \\
\hline
\end{tabular}

The mathematical model of a squirrel-cage induction motor fed by an inverter is developed and simulated by MATLAB. The simulation results are given below for a three-phase non-defected 450W motor. The machine parameters values are given in Table 2 .

Table 2. Squirrel cage induction motor parameters 
Figure 3 and Figure 4 show the induction motor speed and torque respectively under normal condition. The maximum speed value achieved in this condition is about $310 \mathrm{rad} / \mathrm{sec}$ that still maintained within $0,5 \mathrm{sec}$. The starting torque is about $7.5 \mathrm{Nm}$ and is variable from 0 to $0.3 \mathrm{sec}$ as shown in Figure 4 . During the steady-state, oscillations appear at the speed and the electromagnetic torque curves.

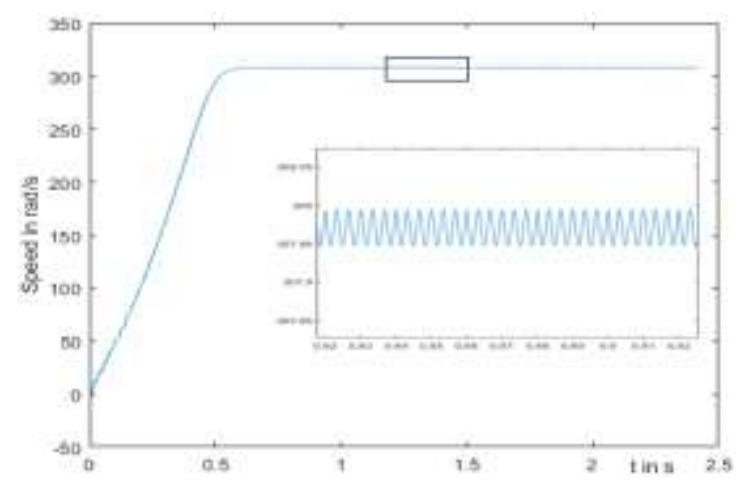

Figure 3. The induction motor speed

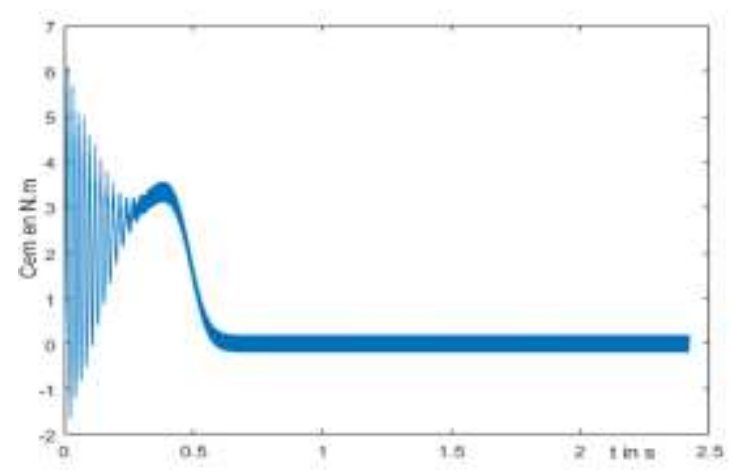

Figure 4. Electromagnetic torque

\section{AUXILIARY WINDING VOLTAGE PARK COMPONENTS}

The method consists of inserting an auxiliary winding which is a small coil "sneak" that forms an angle $\theta_{0}$ with the $\mathrm{A}$ stator phase as shown in Figure 5. This coil has no conductive contact with the other phases but it is mutually coupled with all the other circuits on both the stator and rotor sides. This technic was applied previously for a wound rotor induction motor [15-24, 25].

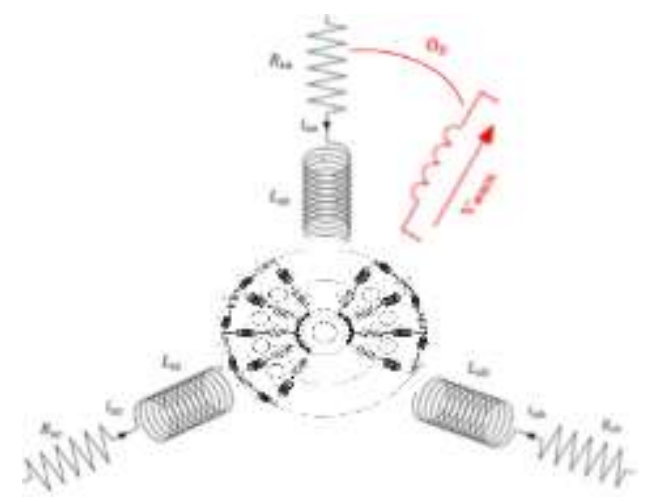

Figure 5. Auxiliary winding emplacement inside the squirrel cage induction motor

The position of this added coil is chosen that all electrical magnitudes can be measured such as voltage and flux. The Lissajous curve of the auxiliary winding voltage Park components is the major criterion of the proposed method, monitoring this factor enabling efficient detection of failures. For that purpose, the auxiliary winding voltage expression is the main key of this technic.

\subsection{Diagnostic system mathematical model}

\subsubsection{Auxiliary winding voltage}

After Applying the fourth order Runge-Kutta method to resolve numerically the differential matrix in (14), we obtain the current vector used to determine the auxiliary winding flux [15-25]

$$
\varphi_{\text {aux }}=a \mathrm{I}_{\mathrm{sa}}+b \mathrm{I}_{\mathrm{sb}}+c \mathrm{I}_{\mathrm{sc}}+\sum_{i=1}^{\mathrm{Nr}} d_{j} \mathrm{I}_{\mathrm{r} i}
$$

The coefficients $a, b, c$ and $d_{j}$ depend on the angle $\theta_{0}$ such as: 


$$
\begin{aligned}
& a=\mathrm{M}_{\text {saux }} \cos \left(\theta_{0}\right) \\
& b=\mathrm{M}_{\text {saux }} \cos \left(\frac{2 \pi}{3}-\theta_{0}\right) \\
& c=\mathrm{M}_{\text {saux }} \cos \left(\frac{4 \pi}{3}-\theta_{0}\right) \\
& d_{j}=\mathrm{M}_{\text {raux }} \cos \left(\theta+\frac{j \pi}{3}\right), j=0,2,4 \ldots
\end{aligned}
$$

$\mathrm{M}_{\text {saux }}, \mathrm{M}_{\text {raux }}$ are the stator and rotor auxiliary winding mutual inductances respectively.

The flux in (19) lead to the auxiliary winding voltage expression:

$$
\mathrm{V}_{\mathrm{aux}}=\frac{\mathrm{d} \varphi_{\mathrm{aux}}}{\mathrm{dt}}
$$

In order to use the Lissajous curve for our model, the determination of the auxiliary winding voltage Park components is essential. For that purpose, it is necessary to apply the Park transformation to the auxiliary winding voltage system in order to obtain the two components $\left(\mathrm{V}_{\mathrm{auxd}}, \mathrm{V}_{\mathrm{auxq}}\right)$, we should consider two other fictive coils forming with the inserting coil a three phase system. Then,

$$
\mathrm{V}_{\mathrm{auxa}}=\frac{\mathrm{d} \varphi_{\mathrm{auxa}}}{\mathrm{dt}}, \mathrm{V}_{\mathrm{auxb}}=\frac{\mathrm{d} \varphi_{\mathrm{auxb}}}{\mathrm{dt}}, \mathrm{V}_{\mathrm{auxc}}=\frac{\mathrm{d} \varphi_{\mathrm{auxc}}}{\mathrm{dt}}
$$

With,

$$
\left[\begin{array}{c}
\varphi_{\text {auxa }} \\
\varphi_{\text {auxb }} \\
\varphi_{\text {auxc }}
\end{array}\right]=[\mathrm{A}]_{3 \times \mathrm{Nr}}\left[\begin{array}{c}
\mathrm{I}_{\mathrm{sa}} \\
\mathrm{I}_{\mathrm{sb}} \\
\mathrm{I}_{\mathrm{sc}} \\
\mathrm{I}_{\mathrm{r} 1} \\
\vdots \\
\mathrm{I}_{\mathrm{rNr}}
\end{array}\right]
$$

[A] is the coefficients matrix when $\theta_{0}=0$. We choose the angle value equals to zero because using different values of it doesn't have any influence on simulations results. Thus $\varphi_{\text {auxa }}$ is representing as:

$$
\begin{aligned}
& \varphi_{\text {auxa }}=\varphi_{\text {sa }}+\varphi_{\text {sb }}+\varphi_{\text {sc }}+\sum_{i=1}^{N r} \varphi_{\text {ri }} \\
& \varphi_{\text {auxa }}=M_{\text {saux }} \mathrm{I}_{\text {sa }}-\frac{\mathrm{M}_{\text {saux }}}{2} \mathrm{I}_{\mathrm{sb}}-\frac{\mathrm{M}_{\mathrm{saux}}}{2} \mathrm{I}_{\mathrm{sc}}+\sum_{i=1}^{\mathrm{Nr}} \mathrm{M}_{\text {raux }} \cos \left(\theta+\frac{j \pi}{3}\right) \mathrm{I}_{\mathrm{ri}}, \mathrm{j}=0,2,4 \ldots
\end{aligned}
$$

The flux Park components is defined as:

$$
\begin{aligned}
& \varphi_{\text {auxad }}=\sqrt{\frac{3}{2}}\left(\varphi_{\text {auxa }} \cos \left(\theta_{0}\right)+\varphi_{\text {auxb }} \cos \left(\theta_{0}-\frac{2 \pi}{3}\right)+\varphi_{\text {auxc }} \cos \left(\theta_{0}-\frac{4 \pi}{3}\right)\right) \\
& \varphi_{\text {auxaq }}=-\sqrt{\frac{3}{2}}\left(\varphi_{\text {auxa }} \sin \left(\theta_{0}\right)+\varphi_{\text {auxb }} \sin \left(\theta_{0}-\frac{2 \pi}{3}\right)+\varphi_{\text {auxc }} \sin \left(\theta_{0}-\frac{4 \pi}{3}\right)\right)
\end{aligned}
$$

The expressions of the auxiliary winding voltage Park components are obtained from the derivatives of its flux Park components such as:

$$
V_{\text {auxad }}=\frac{d \varphi_{\text {auxad }}}{d t} \text { and } V_{\text {auxq }}=\frac{d \varphi_{\text {auxq }}}{d t}
$$

Where,
$\varphi_{\text {auxad }}$ is the direct component of the auxiliary winding flux.
$\varphi_{\text {auxaq }}$ is the indirect component of the auxiliary winding flux.
$V_{\text {auxad }}$ is the direct component of the auxiliary winding voltage.
$V_{\text {auxaq }}$ is the indirect component of the auxiliary winding voltage 


\section{AUXILIARY WINDING VOLTAGE SIMULATION RESULTS}

The simulations were performed for a non-loaded machine fed by an inverter and for a $0.5 \mathrm{Nm}$ and $1.5 \mathrm{Nm}$ loaded machine, this step is necessary to build an efficient knowledge about the machine state. The Lissajous curve of the auxiliary winding voltage Park components is considered as an index of the squirrelcage induction motor quality which informs us about the working conditions of the machine.

The curves obtained in the case of a healthy motor fed by an inverter are considered as a reference to which the results obtained in the next study presenting the broken bar motor cases will be compared. Figure 6(a) shows the Lissajous curve of the auxiliary winding voltage Park components. It has a flower shape with six petals representing the number of the inverter switches. This shape clearly shows the difference between the squirrel cage motor fed by an inverter and the one fed by a sinusoidal voltage source where the Lissajous curve is a circle as shown in Figure 6(b).

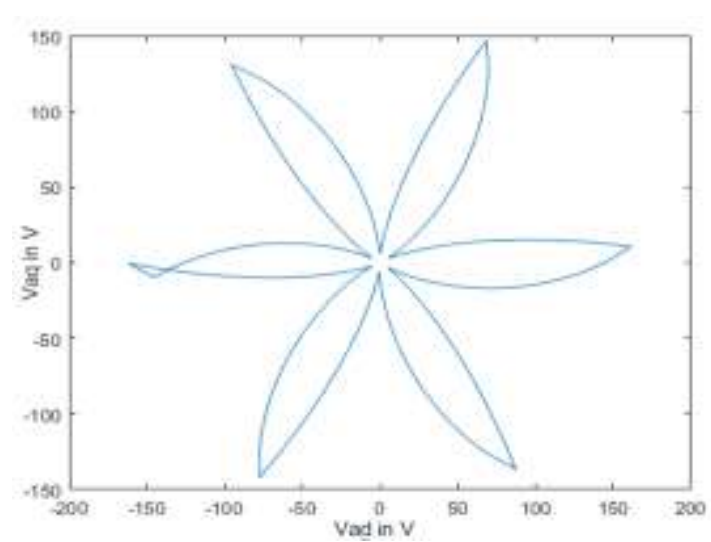

(a)

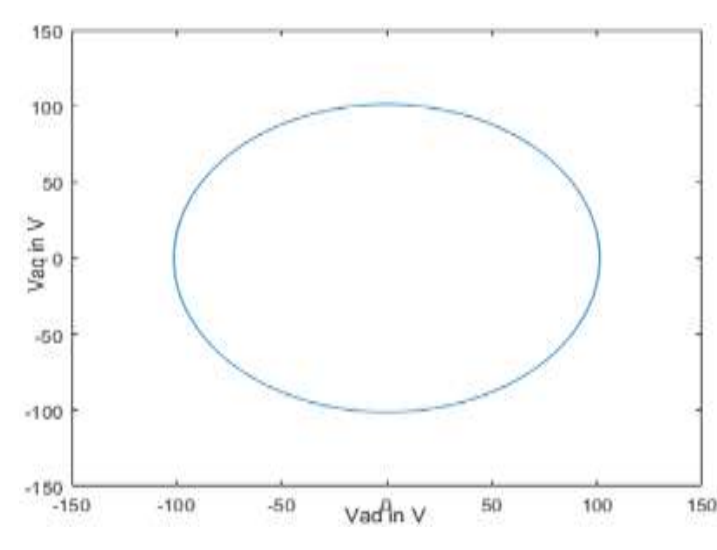

(b)

Figure 6. Lissajous curve of auxiliary winding voltage Park components in case of a no-loaded motor, (a)motor fed by an inverter, (b) motor fed by a sinusoidal voltage

Two sec after its starting, the motor is loaded with $\mathrm{Cr}=0.5 \mathrm{Nm}$ and then with $\mathrm{Cr}=1.5 \mathrm{Nm}$. The figures below show the Lissajous curve of auxiliary winding voltage Park component in the case of different loads. When the load increase, the flower becomes wider and its six petals widened also. The maximum value changes from about $200 \mathrm{~V}$ to $300 \mathrm{~V}$ as shown in Figure 7. The flower orientation also changes according to the level of the load. The change of the Lissajous curve shape approves clearly the validity of this technic in the case of a healthy squirrel cage motor. The change of the Lissajous curve shape approves clearly the validity of this technic in the case of a healthy squirrel cage motor.

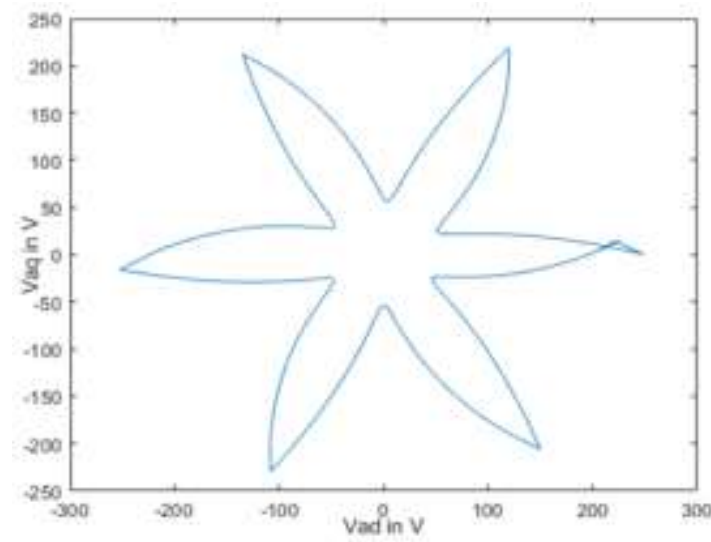

(a)

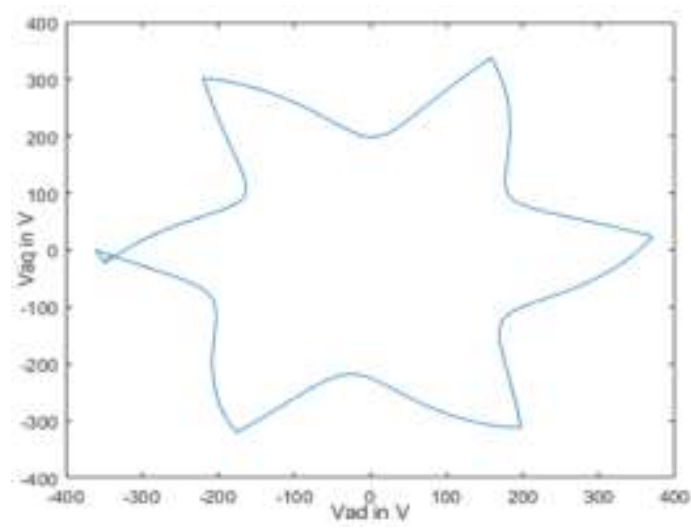

(b)

Figure 7. Lissajous curve of auxiliary winding voltage Park components, (a) In case of $\mathrm{Cr}=0.5 \mathrm{Nm}$, (b) In case of $\mathrm{Cr}=1.5 \mathrm{Nm}$ 


\section{CONCLUSION}

In this paper, a new technic to diagnose the squirrel cage induction motor fed by an inverter is presented. It is based on Lissajous curve of an auxiliary winding voltage Park components. The method was verified by simulation for a healthy combination motor-inverter. It gives satisfactory results when the machine is loaded at different levels. The shape of the Lissajous curve is a flower with six petals that widens proportionally with the motor load. The efficiency of this approach mainly depends on monitoring the Lissajous curve behaviour of an auxiliary winding voltage Park components. The implementation of this diagnosis approach in the cases of the motor broken bars and its broken end rings faults detection will be presented in a future work.

\section{REFERENCES}

[1] J. Y. Khadouj and E. M. Lamiaà, "Electromechanical Conversion Chain Fault Diagnostic - State of Art," vol. 36, pp. 1-5, 2018.

[2] X. Liang, "Condition monitoring techniques for induction motors," 2017 IEEE Ind. Appl. Soc. Annu. Meet. IAS 2017, vol. 2017-January, pp. 1-10, 2017, doi: 10.1109/IAS.2017.8101860.

[3] M. Riera-Guasp, J. A. Antonino-Daviu, and G. A. Capolino, "Advances in electrical machine, power electronic, and drive condition monitoring and fault detection: State of the art," IEEE Trans. Ind. Electron., vol. 62, no. 3, pp. 1746-1759, 2015, doi: 10.1109/TIE.2014.2375853.

[4] W. T. Thomson, "Current Signature Analysis for Condition Monitoring of Cage Induction Motors: Industrial Application and Case Histories," pp. 1-37, 2017.

[5] W. T. Thomson, "Current Signature Analysis for Condition Monitoring of Cage Induction Motors: Industrial Application and Case Histories," pp. 79-118, 2017.

[6] A. Bouzida, O. Touhami, R. Ibtiouen, A. Belouchrani, M. Fadel, and A. Rezzoug, "Fault diagnosis in industrial induction machines through discrete wavelet transform," IEEE Trans. Ind. Electron., vol. 58, no. 9, pp. 4385-4395, 2011, doi: 10.1109/TIE.2010.2095391.

[7] O. Abdi Monfared, A. Doroudi, and A. Darvishi, "Diagnosis of rotor broken bars faults in squirrel cage induction motor using continuous wavelet transform," COMPEL - Int. J. Comput. Math. Electr. Electron. Eng., vol. 38, no. 1, pp. 167-182, 2019, doi: 10.1108/COMPEL-11-2017-0487.

[8] Y. Liu, L. Guo, Q. Wang, G. An, M. Guo, and H. Lian, "Application to induction motor faults diagnosis of the amplitude recovery method combined with FFT,” Mech. Syst. Signal Process., vol. 24, no. 8, pp. 2961-2971, 2010, doi: 10.1016/j.ymssp.2010.03.008.

[9] M. Pineda-sanchez and J. a Antonino-daviu, "Fractional Fourier Domain,” vol. 59, no. 1, pp. 1-11, 2009.

[10] P. K. Kankar, S. C. Sharma, and S. P. Harsha, "Rolling element bearing fault diagnosis using autocorrelation and continuous wavelet transform," JVC/Journal Vib. Control, vol. 17, no. 14, pp. 2081-2094, 2011, doi: 10.1177/1077546310395970.

[11] O. Duque-Perez, L. A. Garcia-Escudero, D. Morinigo-Sotelo, P. E. Gardel, and M. Perez-Alonso, "Analysis of fault signatures for the diagnosis of induction motors fed by voltage source inverters using ANOVA and additive models,” Electr. Power Syst. Res., vol. 121, pp. 1-13, 2015, doi: 10.1016/j.epsr.2014.11.021.

[12] F. Immovilli, S. Member, A. Bellini, R. Rubini, C. Tassoni, and S. Member, "Diagnosis of Bearing Faults in Induction Machines by Vibration or Current Signals : A Critical Comparison," vol. 46, no. 4, pp. 1350-1359, 2010.

[13] H. A. H. Al-Khazali, "Geometrical and Graphical Representations Analysis of Lissajous Figures in Rotor Dynamic System,” IOSR J. Eng., vol. 02, no. 05, pp. 971-978, 2012, doi: 10.9790/3021-0205971978.

[14] A. Elfadili, F. Giri, H. Ouadi, A. El Magri, L. Dugard, and A. Abouloifa, "Induction Motor Control through AC/DC/AC Converters," pp. 1755-1760, 2010.

[15] M. J. Ryan, R. D. Lorenz, and R. W. De Doncker, "Modeling of multileg sine-wave inverters: A geometric approach," IEEE Trans. Ind. Electron., vol. 46, no. 6, pp. 1183-1191, 1999, doi: 10.1109/41.808008.

[16] A. Ibrahim and M. Marei, "Modeling of induction motor based on winding function theory to study motor under stator/rotor internal faults," IEEE proceedings, MEPCON, no. 1, pp. 494-500, 2010, [Online]. Available: http://www.sdaengineering.com/mepcon10/Papers/215.pdf.

[17] G. Didier, "Modélisation Et Diagnostic De La Machine Asynchrone En Présence De Défaillances," Techniques, 2004, doi: http://www.theses.fr/2004NAN10163.

[18] M. Sahraoui and A. Ghoggal, "Modelling and Detection of Inter-Turn Short Circuits in Stator Windings of Induction Motor," pp. 4981-4986.

[19] I. Ouachtouk, S. El Hani, S. Guedira, K. Dahi, and H. Mediouni, "Broken rotor bar fault detection based on stator current envelopes analysis in squirrel cage induction machine," 2017 IEEE Int. Electr. Mach. Drives Conf. IEMDC 2017, pp. 2-7, 2017, doi: 10.1109/IEMDC.2017.8002142.

[20] G. Bossio, C. De Angelo, J. Solsona, G. Garcia, and M. I. Valla, "A 2-D model of the induction machine: An extension of the modified winding function approach," IEEE Trans. Energy Convers., vol. 19, no. 1, pp. 144-150, 2004, doi: 10.1109/TEC.2003.822294.

[21] M. Ojaghi, M. Sabouria, J. Faizb, and V. Ghorbanianb, "Exact modeling and simulation of saturated induction motors with broken rotor bars fault using winding function approach," Int. J. Eng. Trans. A Basics, vol. 27, no. 1, pp. 69-78, 2014, doi: 10.5829/idosi.ije.2014.27.01a.10.

[22] R. S. Harmonics, "Park Model of Squirrel Cage Induction Mohamed Boucherma - Mohamed Yazid Kaikaa," vol. 57, no. 4, pp. 193-199, 2006. 
[23] L. El Menzhi and A. Saad, "Three phase induction motor inverter defects diagnosis using voltage spectrum of an auxiliary winding," Appl. Mech. Mater., vol. 672-674El, pp. 1244-1252, 2014, doi: 10.4028/www.scientific.net/AMM.672-674.1244.

[24] L. El Menzhi and A. Saad, "Induction motor fault diagnosis using voltage spectrum of auxiliary winding and lissajous curve of its park components," Adv. Mater. Res., vol. 805-806, pp. 963-979, 2013, doi: 10.4028/www.scientific.net/AMR.805-806.963.

[25] L. El Menzhi and A. Saad, "Lissajous curve of an auxiliary winding voltage park components for diagnosing multiple open switches faults in three phase inverter," Appl. Mech. Mater., vol. 672-674, pp. 1224-1233, 2014, doi: 10.4028/www.scientific.net/AMM.672-674.1224.

\section{BIOGRAPHIES OF AUTHORS}
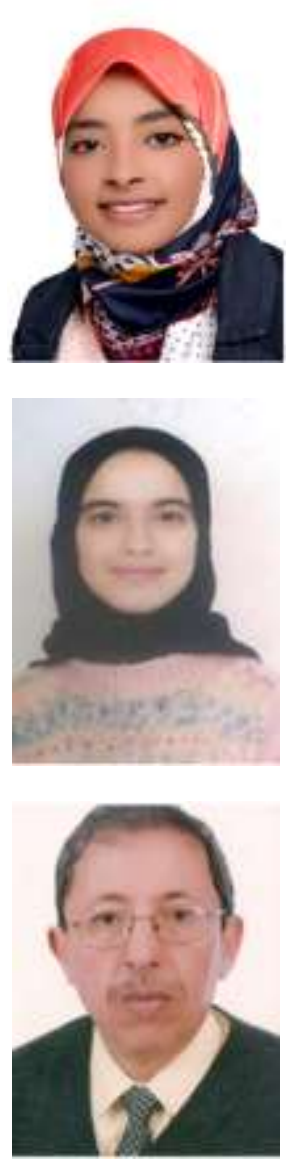

Yakout Khadouj Jelbaoui was born in Morocco in July 1992. In 2015, she received the Engineer degree in Mechatronics from the National School of Applied Sciences, Abdelmalek Essaadi University of Morocco in Tetouan. She is a $\mathrm{PhD}$ student in Electricotechnical engineering at National School of Applied Sciences in Tangier since November 2016. She is interested in electrical machines and electrical devices modeling, control and on-line diagnosis defects

Lamiaa El Menzhi is a professor at AbdelamalekEssaadi University in Morocco since 2010. On 2002, She got her High Deepened Studies Diploma in electrical engineering from the High National School of Electricity and Mechanics ENSEM in Hassan 2 University in Casablanca. From 2002 until 2004, she was a research student in one of the universities in Japan. On 2009, she obtained her Doctor degree, then her Habilitation as a professor researcher on 2016 from Hassan 2 University in Casablanca (ESEM). She is interested in electrical machines control and on-line diagnosis either used as a motor or a generator in wind turbines. Lamiaa El Menzhi is a member and advisor of the Moroccan Center of Polytechnical Research and Innovation since 2015.

Abdallah Saad was born in Morocco in September 1956. He received the Engineer and Doctor of Engineering degrees from National Polytechnic Institute of Grenoble France respectively in 1980 and 1982. From 1982 to 1986, he was Researcher at French National Center for Scientific Research (CNRS) - Electrostatics and Dielectric Materials Laboratory Grenoble. After receiving the Doctor of Physical Sciences degree in 1986, he joined Hassan 2 University of Morocco. Professor of electrical engineering, he has several scientific and educational responsibilities. His main fields of interest are High Voltage and Electrical Insulations, modeling and control, renewable energy integration 